\title{
Occupational dermatoses reported in Brazil from 2007 to 2014*
}

\author{
Michelle Larissa Zini Lise ${ }^{1}$ \\ Michael Laurence Zini Lise ${ }^{3}$ \\ Luis Carlos Elejalde de Campos ${ }^{1}$
}

\author{
Fernando Ribas Feijó ${ }^{2}$ \\ Claudia Ribeiro Zini Lise ${ }^{4}$
}

DOI: http://dx.doi.org/10.1590/abd1806-4841.20185314

\begin{abstract}
BACKGROUND: Occupational diseases are very prevalent in the world, especially in developing countries. Occupational dermatoses are responsible for most of these cases. However, epidemiological studies are rare in Brazil.

OвјЕстіvEs: To verify the panorama of occupational skin diseases in Brazil describing frequencies of work-related dermatoses and their sociodemographic and occupational patterns.

Methods: We used retrospective data from the Notifiable Diseases Information System, (from 2007-2014) tabulated with the Tab program for Windows - TabWin12. We used intentional non-probability sampling and sequential selection, considering all notified occupational dermatoses.

RESULTS: All cases of occupational dermatoses referred to in the period were analyzed $(n=4710)$. Males and the age group of 3549 years were the most affected. The most affected body area was the upper limb $(34.2 \%)$ and the hand $(25.4 \%)$. The "causative agent" field in the forms was not filled in $69.4 \%$ of cases, with chrome as the most prevalent cause reported (11.8\%). ICD-10 codes more prevalent were L23, L24, and L25, corresponding to $34.2 \%$ of the sample. In total, $29 \%$ of patients needed to take a sick leave. No cases evolved to death and there were $0.2 \%$ of total as permanent disability.

STUDY LIMITATIONS: The amount of missing information for various items in the system draws attention.

Conclusions: Treatment of patients with occupational dermatitis include the identification and removal of the causative agent and specific treatment of the disease. Diagnosis delay in cases of occupational dermatoses brings social and financial consequences to the work and life of workers.
\end{abstract}

Keywords: Dermatitis, contact; Dermatitis, Occupational; Occupational diseases; Eczema

\section{INTRODUCTION}

Occupational diseases are an important issue in the Brazilian political and social contexts. For this reason, three ministries are involved in their control: Labor and Social Security, Justice and Citizenship, and Health ministries. Among occupational diseases, occupational dermatoses (ODs) are one of the most frequent, corresponding to $60 \%$ of the occupational diseases in developing countries. ${ }^{1,2}$

ODs are defined as any change in the skin or mucosa, directly or indirectly caused, conditioned, maintained, or aggravated by agents present in the professional activity or in the workplace. ${ }^{2} \mathrm{~A}$ wide variety of agents can cause ODs. Likewise, ODs can manifest in different ways, including allergic and irritative contact dermatitis, actinic keratoses, neoplasias, dermatophytoses, occupational acne (elaioconiosis and chloracne), foreign body granulomas, infec- tions, nail changes, ulcerations, burns, among others. ${ }^{2}$

Various agents present in the workplace are associated with the development of ODs. The most common include chemical agents (metals, acids and alkalis, aromatic hydrocarbons, lubricants, cutting oils, and arsenic), physical agents (radiation, trauma, vibration, pressure, heat, and cold), and biological agents (viruses, bacteria, fungi, parasites, plants, and animals). ${ }^{2}$

It is estimated that more than 13 million workers in the United States are exposed to chemicals that can be absorbed through the skin. It is known that chemical exposure on skin can result in a variety of occupational diseases, including skin diseases and others with systemic repercussions. ${ }^{3}$

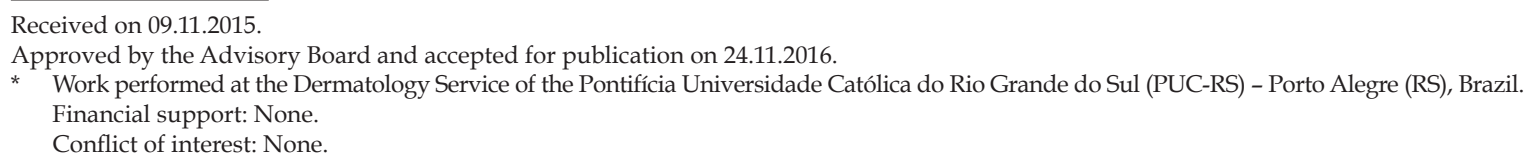


Chemical agents are the primary cause of occupational skin diseases. Among those that cause contact dermatitis, primary irritants and sensitizers are found. Primary irritants act directly on the skin through local aggressive chemical reactions. Sensitizers, in turn, do not produce immediate reactions, inducing allergic reactions after a period of exposure. ${ }^{3}$ Therefore, contact dermatitis (CDs) are classified into irritant contact dermatitis (ICD) and allergic contact dermatitis (ACD). ${ }^{2}$ Together, they are responsible for an annual cost of more than US\$ 1 billion in the United States. ${ }^{3}$ According to the Center for Disease Control and Prevention, CDC (2013), the productive sectors most commonly affected by ODs are food, cosmetology, health, agriculture, cleaning, painting, mechanics, printing/ lithography, and construction industries. ${ }^{3}$ In developing countries, it is estimated that about $1 \%$ of workers have occupational dermatoses. Of these, contact dermatitis accounts for $80-95 \%$ of all cases. ${ }^{1,2,4}$

A 2010 study with 630 outpatients of the Santa Casa de São Paulo Dermatology Clinic found that $10.9 \%$ had occupational contact dermatitis. The prevalent occupations in the study included domestic workers $(39 \%)$, construction workers (33.5\%), metallurgists $(6 \%)$, carpenters $(4 \%)$, and hairdressers $(4 \%)$. Among patients with occupational contact dermatitis, $91.5 \%$ worked in a humid environment. ${ }^{1}$

Epidemiological studies on ODs in Brazil are rare. This fact, together with underdiagnosis and underreporting, makes it difficult to collect and analyze data on the subject. In addition, many workers do not seek health care because they fear losing their jobs. ${ }^{2}$

Until 2005, OD notifications were restricted to workers registered in the Brazilian General Social Security Regime (RGPS) through the issuance of a work accident notice (CAT), a form created in 1967. All occupational accidents or diseases had to be reported by the company to the Brazilian National Social Security Institute (INSS), subject to fine in case of omission. The information in the form is important not only for social, statistical, and epidemiological references, but also for social security matters. ${ }^{5}$ Thus, in the case of occupational dermatoses, Brazilian data are derived from INSS records. However, a new notification system was implemented in 2006, called SINAN (National Disease Notification System).

Through this System, work-related health problems (which include occupational accidents and occupational diseases) began to be notified and organized in a national network, with the purpose of recording the data of persons assisted in the Brazilian unified health system, (SUS). SINAN is a universal notification system, which covers all workers, regardless of whether they have an employment relationship or not. Any diagnosed OD must be reported through the SINAN.

The present study aimed to verify the panorama of occupational skin diseases in Brazil based on data obtained from SINAN. Their frequencies and sociodemographic patterns are herein described.

\section{METHODS}

This is a cross-sectional study based on secondary data. We used SINAN data from 2007-2014, tabulated with the TabWin program for Windows. ${ }^{6}$

We conducted our study using retrospective data from SINAN, which is freely available online. SINAN used intentional and non-probability sampling with sequential selection, including all cases of occupational dermatoses notified by health professionals from SUS in the period.

The notified occupational dermatoses were categorized according to the International Classification of Diseases, tenth revision (ICD10). We used the codes and numbers according to the main diagnoses of the diseases, grouping the diseases that had the same main code.

We used descriptive statistics to show the frequencies and percentages of OD cases over the years. Graphs and tables illustrate the analyzed data.

\section{RESULTS}

In total, there were 4,710 cases notified as OD in the period. The most affected age group was 35-49 years, with 1,852 cases (39.3\%). The other age groups reported were: $20-34$ years, 1,558 cases (33.1\%); 50-64 years, 955 cases (20.3\%); 64 years, 174 cases $(3.7 \%)$; and less than 20 years, 171 cases (3.6\%). Males were the most affected in all the years surveyed, with 3,025 cases (64.2\%).

Graph 1 gives information about the level of education achieved by workers: 2,635 (55.9\%) had not completed high school; 996 (21.1\%) completed high school; and only 141 (3.0\%) held a university diploma.

Skin color was described as black or brown in 2,061 cases $(43.7 \%)$; as white, in 1,748 cases (37.1\%); and without records, in 848 cases $(18 \%)$.

Regarding workers' affected by dermatoses area of residence, 3,814 individuals (81.0\%) were urban residents and 379 $(8.05 \%)$ lived in rural areas. However, in 501 forms (10.6\%), health professionals ignored or failed to fill this field.

Among the cases of OD, the prevalent ICD-10 codes refer to CDs (L23, L24, and L25), corresponding to $34.2 \%$ of the sample. Among the forms of CDs, ACD (L23) was the most frequent, followed by dermatitis caused by exposure to non-ionizing radiation (L57),

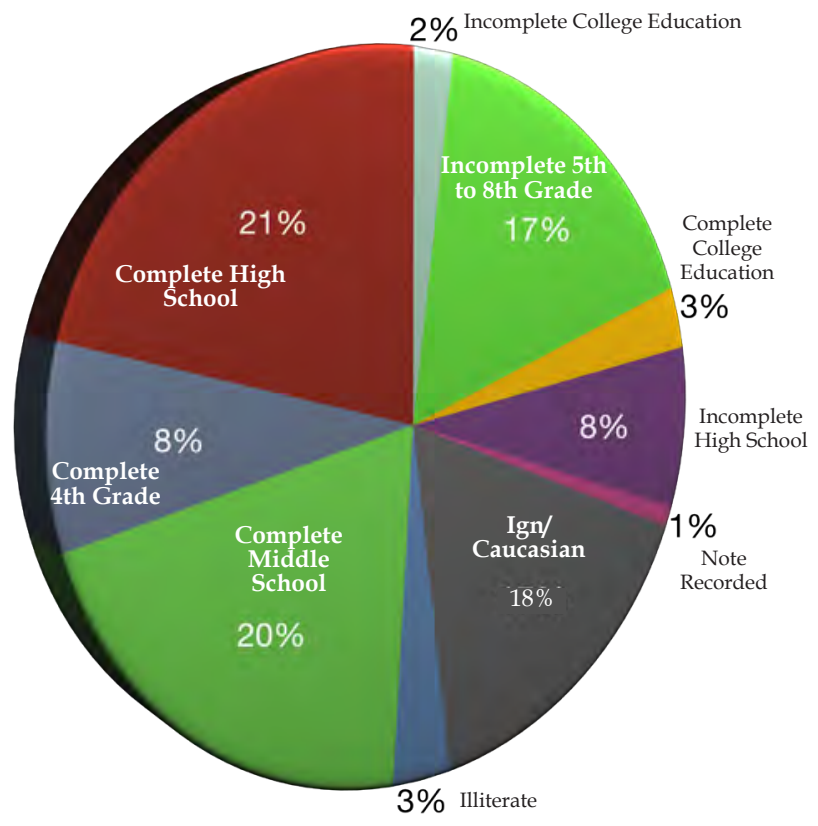

Source: SINAN/SVS

Graph 1: Distribution of notified cases by educational level, Brazil, 2007-2014 
corresponding to $26.2 \%$ of the notified cases. In $14.4 \%$ of the sample, the reports did not specify the type of OD (L98), describing only general data of the disease. The frequencies are shown in graph 2 .

In 2007,39 cases (30.5\%) evolved with temporary incapacity. In 2014, this number was as high as 104 (15.2\%). No dermatoses led to death and 9 cases $(0.2 \%)$ progressed with permanent disability (Table 1).

Data show that absences from work decreased proportionately during the period, from $58.6 \%$ in 2007 to $27.8 \%$ in 2014 . In total, $49.3 \%$ of the workers did not require to take a sick leave, whereas $29 \%$ needed to take a sick leave and $21.6 \%$ of the reports had no information on absenteeism.

Ambulatory care was the most frequent type of treatment (3,494 or $74.2 \%)$, and only $4.1 \%$ of the workers needed hospitalization. The treatment regimen was not described in $21.7 \%$ of the cases. The type of employment relationship was marked as ignored or left blank in all notified cases. The type of lesion was not described.

Table 2 shows the number of CAT forms emitted by SINAN in the period studied.

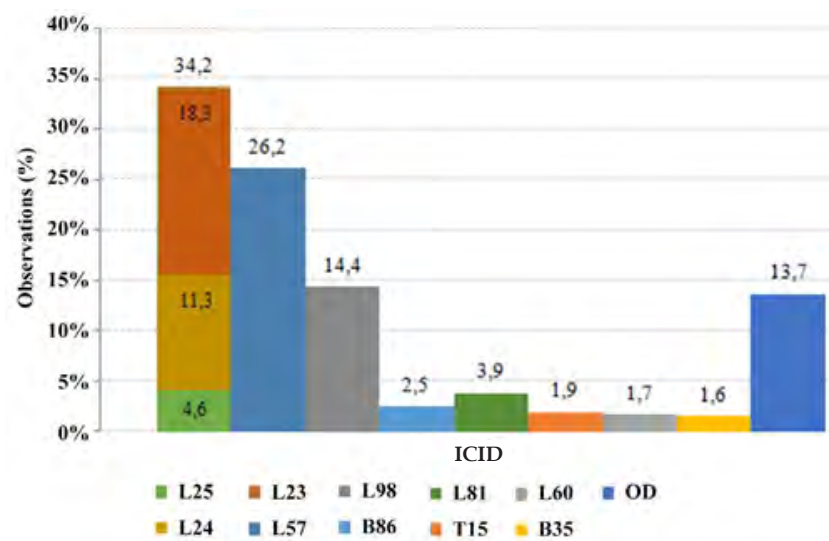

Source: SINAN/SVS

GraPH 2: Distribution of ODs according to ICD-10

Legend: L25 - Unspecified contact dermatitis. L24 - Irritant contact dermatitis. L23 - Allergic contact dermatitis. L57 - Skin changes due to chronic exposure to nonionizing radiation. L98 - Other disorders of skin and subcutaneous tissue, not elsewhere classified. B86 - Scabies. L81 - Other disorders of pigmentation. T15 - Foreign body on external eye. L60 - Nail disorders. B35 - Dermatophytosis. OD - Other dermatoses
Table 3 shows the local of lesion. The most affected areas were the upper limbs $(1,610$ or $34.2 \%)$, including the hand $(1,197$ or $25.4 \%$ ) and the upper limb - generally described in 413 cases $(8.8 \%)$; head $(1,297$ or $27.5 \%)$; lower limb (387 or $8.2 \%$ ), which includes the feet $(228$ or $4.8 \%)$, and the entire body (385 or $8.2 \%$ ).

The "causal agent" field was not completed or was marked as unknown in $69.4 \%$ of the cases in the period. The most common agents reported are described in table 4 .

\section{DISCUSSION}

Data from industrialized countries indicate that ODs account for $60 \%$ of all occupational diseases. ${ }^{2}$ In the UK, the incidence is estimated at 13 per 100,000 population per year and the prevalence at 15 per 10,000 population. High-risk occupations include hairdressers, assemblers, oil industry workers, machine operators, and print workers. ${ }^{7}$ In the printing industry, the overall prevalence of occupational skin diseases is estimated at $40 \%{ }^{8}$ According to a Scottish study, the risk of developing $\mathrm{CD}$ among hairdressers was 86.4 per 100,000 population. ${ }^{9}$ Bradshaw et al. also analyzed work-related symptoms among hairdressers, identifying a $41 \%$ prevalence of cutaneous symptoms. ${ }^{10}$ The most prevalent age group was 35-49 years, followed by the age group 20-34 years. A previous national study indicates that the age of the affected individuals was compatible with the age of greater professional activity of the population. ${ }^{1}$

Across the world, skin diseases resulting from occupational exposure are common and are second only to musculoskeletal diseases as the cause of industrial occupational health problems. ${ }^{4}$ Although occupational dermatitis can appear at any age, its peak occurs at the end of work life. Gawkrodger et al. showed that dermatitis among bakers and hairdressers appears early, unlike workers who come in contact with cement, in which contact dermatitis may take a few years to develop.?

It is known that skin susceptibility is influenced by individual characteristics as well as by environmental factors. ${ }^{11}$ In the studied group, men were the most affected in all the years surveyed, with a mean of $64.23 \%$ of the cases. It is also known that women are more likely to develop hand eczema and that working in wet conditions favors its occurence. ${ }^{12}$ Personal factors, such as atopy and metal allergy, have also been identified as risk factors for hand dermatitis. ${ }^{13}$ However , checking for the presence of other concomitant

\begin{tabular}{|lccccccccccc} 
& \multicolumn{1}{c}{ TABLE 1: Evolution of disability caused by occupational dermatoses } \\
\multicolumn{1}{c}{ EVOLUTION } & $\mathbf{2 0 0 7}$ & $\mathbf{2 0 0 8}$ & $\mathbf{2 0 0 9}$ & $\mathbf{2 0 1 0}$ & $\mathbf{2 0 1 1}$ & $\mathbf{2 0 1 2}$ & $\mathbf{2 0 1 3}$ & $\mathbf{2 0 1 4}$ & Total & \% \\
\hline Unknown/blank & 45 & $\mathbf{7 5}$ & 105 & 106 & 163 & 121 & 138 & 96 & 849 & 18.0 \\
\hline Cure & 21 & 127 & 116 & 99 & 121 & 147 & 134 & 114 & 879 & 18.7 \\
\hline Non-confirmed cure & 9 & 22 & 33 & 64 & 48 & 67 & 61 & 38 & 342 & 7.2 \\
\hline Temporary disability & 39 & 52 & 61 & 118 & 111 & 142 & 100 & 104 & 727 & 15.4 \\
\hline Permanent partial disability & 10 & 10 & 11 & 9 & 12 & 14 & 10 & 8 & 84 & 1.8 \\
\hline Permanent total disability & 0 & 0 & 2 & 1 & 1 & 3 & 1 & 1 & 9 & 0.2 \\
\hline Others & 4 & 13 & 63 & 110 & 236 & 522 & 546 & 325 & 1819 & 38.7 \\
\hline Total & $\mathbf{1 2 8}$ & $\mathbf{2 9 9}$ & $\mathbf{3 9 1}$ & $\mathbf{5 0 7}$ & $\mathbf{6 9 2}$ & $\mathbf{1 0 1 6}$ & $\mathbf{9 9 0}$ & $\mathbf{6 8 6}$ & $\mathbf{4 7 0 9}$ & $\mathbf{1 0 0}$
\end{tabular}

Source: SINAN/SVS 


\begin{tabular}{|c|c|c|c|c|c|c|c|c|c|c|}
\hline Year & 2007 & 2008 & 2009 & 2010 & 2011 & 2012 & 2013 & 2014 & Total & $\%$ \\
\hline Unknown/blank & 33 & 54 & 75 & 81 & 152 & 131 & 130 & 69 & 725 & 15.39 \\
\hline Yes & 51 & 97 & 107 & 111 & 113 & 113 & 107 & 87 & 786 & 16.69 \\
\hline No & 31 & 39 & 112 & 232 & 363 & 732 & 692 & 467 & 2668 & 56.65 \\
\hline Non applicable & 13 & 109 & 98 & 83 & 64 & 40 & 61 & 63 & 531 & 11.27 \\
\hline Total & 128 & 299 & 392 & 507 & 692 & 1016 & 990 & 686 & 4710 & 100 \\
\hline$\%$ & 2.7 & 6.3 & 8.3 & 10.8 & 14.7 & 21.6 & 21.0 & 14.6 & 100 & \\
\hline
\end{tabular}

Source: SINAN/SVS

\begin{tabular}{|c|c|c|c|c|c|c|c|c|c|c|}
\hline Location/Year & 2007 & 2008 & 2009 & 2010 & 2011 & 2012 & 2013 & 2014 & Total & $\%$ \\
\hline Head & 1 & 21 & 38 & 56 & 144 & 349 & 417 & 271 & 1297 & 27.54 \\
\hline Hand & 41 & 97 & 107 & 170 & 200 & 254 & 175 & 153 & 1197 & 25.41 \\
\hline Upper limb & 23 & 50 & 43 & 55 & 62 & 73 & 57 & 50 & 413 & 8.77 \\
\hline Whole body & 27 & 33 & 60 & 48 & 61 & 63 & 60 & 33 & 385 & 8.17 \\
\hline Foot & 2 & 14 & 15 & 24 & 48 & 40 & 52 & 33 & 228 & 4.84 \\
\hline Lower limb & 4 & 13 & 16 & 22 & 31 & 37 & 16 & 20 & 159 & 3.38 \\
\hline Chest & 1 & 5 & 12 & 12 & 7 & 18 & 9 & 9 & 73 & 1.55 \\
\hline Neck & 0 & 4 & 3 & 8 & 11 & 4 & 5 & 6 & 41 & 0.87 \\
\hline Abdomen & 0 & 2 & 6 & 4 & 4 & 3 & 0 & 0 & 19 & 0.40 \\
\hline Others & 9 & 43 & 29 & 40 & 55 & 98 & 93 & 48 & 415 & 8.81 \\
\hline Unknown/blank & 20 & 17 & 63 & 68 & 69 & 77 & 106 & 63 & 483 & 10.25 \\
\hline Total & 128 & 299 & 392 & 507 & 692 & 1016 & 990 & 686 & 4710 & 100 \\
\hline
\end{tabular}

Source: SINAN/SVS

\begin{tabular}{|lccccccccccc} 
& \multicolumn{1}{c}{ TABLE 4: Causative agent frequencies, Brazil, 2007-2014 } & & \\
\multicolumn{1}{c}{ Agent } & $\mathbf{2 0 0 7}$ & $\mathbf{2 0 0 8}$ & $\mathbf{2 0 0 9}$ & $\mathbf{2 0 1 0}$ & $\mathbf{2 0 1 1}$ & $\mathbf{2 0 1 2}$ & $\mathbf{2 0 1 3}$ & $\mathbf{2 0 1 4}$ & Total & \% \\
\hline Unknown/blank & 64 & 207 & 253 & 310 & 473 & 747 & 732 & 484 & 3270 & 69.4 \\
\hline Chrome & 42 & 40 & 54 & 93 & 93 & 99 & 71 & 62 & 554 & 11.8 \\
\hline Wood & 1 & 3 & 23 & 29 & 42 & 45 & 87 & 48 & 278 & 5.9 \\
\hline Others & 7 & 14 & 18 & 31 & 34 & 51 & 40 & 36 & 231 & 4.9 \\
\hline Solvents & 6 & 11 & 15 & 17 & 24 & 36 & 31 & 31 & 171 & 3.6 \\
\hline Resins & 0 & 8 & 5 & 7 & 4 & 12 & 7 & 5 & 48 & 1.0 \\
\hline Cosmetics & 2 & 3 & 10 & 2 & 6 & 10 & 8 & 5 & 46 & 1.0 \\
\hline Nickel & 2 & 3 & 5 & 7 & 6 & 9 & 3 & 5 & 40 & 0.8 \\
\hline Lubricating greases & 0 & 8 & 5 & 3 & 4 & 4 & 5 & 6 & 35 & 0.7 \\
\hline Plastic & 2 & 1 & 4 & 2 & 3 & 2 & 6 & 3 & 23 & 0.5 \\
\hline Cutting oil & 2 & 1 & 0 & 6 & 3 & 1 & 0 & 1 & 14 & 0.3 \\
\hline Total & $\mathbf{1 2 8}$ & $\mathbf{2 9 9}$ & $\mathbf{3 9 2}$ & $\mathbf{5 0 7}$ & $\mathbf{6 9 2}$ & $\mathbf{1 0 1 6}$ & $\mathbf{9 9 0}$ & $\mathbf{6 8 6}$ & $\mathbf{4 7 1 0}$ & $\mathbf{1 0 0}$
\end{tabular}

\section{Source: SINAN/SVS}

disease is not part of the SINAN communication system so far.

Data on schooling show that, in most cases, workers had a low level of education, since 2,635 patients (55.9\%) failed to finish high school, which could explain some of the accidents. Regarding skin color, brown and black workers represented 2,061 cases (43.7\%) and whites, 1,748 (37.1\%).

Regarding demographic distribution, most workers $(80 \%)$ came from urban areas, which may correspond to the most common place for factories and companies to set up. It is also plausible that ODs in rural areas are less notified because of the difficulties faced by the health system to reach and survey rural workers.

As expected, according to previous studies, CDs were the most common ODs in the studied group (prevalence of $34 \%$ ), but with lower percentages when compared to the literature. Occupational CDs can produce severe and difficult to treat conditions and are often responsible for discomfort, pruritus, trauma, and function- 
al and aesthetic changes that interfere with social life and work. ${ }^{2}$ The prognosis of patients with OD is not good. ${ }^{7}$ Inability is often reported, which may require adaptations or even the worker's rehabilitation for a different position. ${ }^{2}$

In relation to the second most frequent $\mathrm{OD}$, we highlight the large number of cases reported due to lesions caused by exposure to non-ionizing radiation, in particular to sun exposure, as shown in graph 2. Most of these cases correspond to precancerous lesions, such as actinic keratosis. This is valuable information for Dermatology and public health in Brazil due to the large number of workers chronically exposed to solar radiation, especially workers from rural areas and the construction industry.

Data from developed countries show that a high percentage of their workers are exposed to solar ultraviolet radiation (UVR). ${ }^{14}$ It is known that exposure to UVR in the workplace may increase the risk of developing skin cancer for workers. ${ }^{15,16}$ In our sample, only three occupational skin cancer cases were reported. Possibly, this low notification rate stems from the fact that SINAN has a specific form for cancer notification. Therefore, most occupational skin cancers may have been reported in that document, skewing the interpretation of this item. A literature review also shows that occupational skin cancers are underreported in other countries, with a lack of effective preventive measures for ODs in several European countries. $^{14,17}$

Regarding disease evolution, $30.5 \%$ of the cases $(n=39)$ progressed to temporary disability in 2007, with a progressive decrease to $15.2 \%$ (104 cases) in 2014. None of the cases evolved to death and 2 cases $(0.51 \%)$ notified in 2009 revealed total permanent disability. In addition, there was a decrease in the number of cases in which health professionals failed to fill the evolution field, from $35.2 \%$ in 2007 (45 cases) to $14.0 \%$ in 2014 (96 cases).

Despite the variation in the occurrence of incapacity for work resulting from ODs (15-30\% per year in the years studied), this prevalence is relevant both to workers - who may lose their full capacity to work and salary - and employers and the social security system - due to the high costs and absenteeism.

Regarding the issuance of the CAT form, we found that $39.8 \%$ of the notifications in 2007 and $32.4 \%$ in 2008 had concomitant emission of the form. In subsequent years, the proportion of notified cases decreased progressively, with percentages of $27.3 \%$, $21.9 \%, 16.3 \%, 11.1 \%, 10.8 \%$, and $12.6 \%$, respectively over the period 2009-2014. This reduction may be associated with the imposition of the Accident Prevention Factor (FAP) by the INSS. The FAP is a multiplier factor for a Brazilian tax for work injury (SAT), which is levied on companies whose employees have suffered a large number of accidents and injuries at work.

Although it is possible that improvements in preventive measures adopted by companies - such as training sessions and qualification of workers required to use personal protective equipment (PPE) - can explain this reduction, it seems to us much more plausible that the variation in the interest and burden paradigm, with the direct link between the number of accidents at work and the cost of companies has had a negative influence on the issuance of CATs and, consequently, on notifications. Diagnostic errors in the occupational environment are disastrous for the patient, for compa- nies, and for government regulatory agencies. ${ }^{2}$

Regarding lesion site, as expected, the upper limb (8.77\%), in particular the hand $(25.41 \%)$, was the most common affected site ( $34.18 \%$ of the total), while $27.5 \%$ of the lesions were located on the head $(1,297$ cases). On average, in the period studied, $10.3 \%$ of the health professionals patients failed to inform the location of the lesion. In $8.2 \%$ of cases, the lesion affected the entire body. Our data are consistent with the literature stating that the hands are affected alone or with other sites in $80-90 \%$ of OD cases. The arms may be involved if they are not covered, and the face and neck are affected if there is exposure to dust or smoke. Workers exposed to cement often have injuries to their legs, feet, and hands. ${ }^{7}$

Rotter et al. showed that dermatitis affects the hands in $70 \%$ of cases. ${ }^{1}$ Considering the complexity of all possible environments that the hands are exposed to, it is reasonable to believe that they are more susceptible to exposure to irritants (such as water, soap, or food allergens) than other parts of the body. ${ }^{18}$

The "causal agent" field was not completed or was marked as unknown in 3,270 cases $(69.4 \%)$ in the studied period. This figure is extremely high, indicating that health professionals responsible for reporting and surveillance need to qualify the research process, giving emphasis to occupational history during anamnesis. Among the fully completed forms, the most common causal agent was chromium, (36.1\% of cases, $11.8 \%$ of the total). Although problems caused by cement and rubber are common dermatological concerns, no one reported their cases as having been caused by these two substances. Even so, it is likely that most of the reports of chromium as the main causative agent are related to exposure to cement, since chromium is one of the major allergens present in this material. ${ }^{1}$ The major allergens in the study by Duarte and Rotter et al. were: potassium dichromate $(41 \%$ of positive tests); nickel sulfate $(23 \%)$; carba mix $(23 \%)$; cobalt chloride $(20 \%)$; thiuram mix $(19 \%)$; PPD mix (10\%); formaldehyde (7\%); epoxy resin (7\%); and mercaptobenzothiazole $(6 \%){ }^{1}$ SINAN's notification form contains only one field for the causative agent, which does not differentiate the allergen substance from the product containing it. Therefore, it is the health professional's task to complete the form and indicate the main agent. In our opinion, the form could be improved by providing separate fields that discriminate between the main product and the allergenic chemical.

Our data show that, in 2007 and 2008, the number of cases that lead to absences from work was $58.6 \%$ and $49.2 \%$, respectively. We observed a progressive decrease in these figures, reaching $27.8 \%$ in 2014. It is important to note that, in the meantime, $21.6 \%$ of the cases had an unknown progress, or the field about what happened to the worker after the lesion was left blank.

The most reported treatment was outpatient care $(3,471$ or $74.1 \%)$. Again, the number of blank or skipped fields was high $(21.7 \%)$, showing the absence of case monitoring data.

Although laboratory tests can contribute to the diagnosis of ODs, none of them replaces a detailed anamnesis, a careful physical examination, and the knowledge of the products used by workers and the hazards potentially present in workplaces. Patch allergy test (PT), or epicutaneous test, is the best complementary test, which allows differentiation of ICD from ACD. However, a positive patch test will only determine the causal relationship between a substance 
and the clinical picture with a good anamnesis, since prior exposure may also yield a positive test result. ${ }^{2}$

Preventive measures for ODs are extremely important. Companies should take collective measures for protection, provide adequate equipment, and provide medical examinations and periodic guidance to workers in order to prevent re-exposures and new cases. Such conduct is important, since ODs cause discomfort, incapacity for work, decreased production, and may result in the need for a job position change and, consequently, salary and company income reduction, as well as increased costs with health insurance plans and social security. ${ }^{2}$

Delayed diagnosis can result in continued exposure to irritants or allergens and may also adversely affect prognosis. ${ }^{19} \mathrm{In}-$ adequate assessment can have a devastating effect on future working life, with considerable medico-legal implications. ${ }^{19}$ Across the world, changes in labor legislation have resulted in a reduction in the prevalence of allergen reactivity. ${ }^{20}$

Progress in the clinical area - in line with continued surveillance of new allergens in order to replace them in industrial production and product development using less allergenic chemicals - is expected to modify this scenario. ${ }^{20}$

\section{CONCLUSIONS}

The treatment of patients with occupational dermatoses is based on the correct identification and removal of the causative agent associated with the specific treatment of the disease. Preventive measures - such as proper hygiene, use of PPE, clothing, gloves, goggles, barrier creams, and sunscreen when indicated - are essential to prevent the onset of occupational skin diseases. Adequate training for those who handle objects, machines, and chemicals is also a protective factor for the non-development of diseases.

We would like to draw attention to the missing information for various items in the notification form. Similarly, many fields were marked as ignored or left blank. This was initially justified because the system was in the implementation process in the period. Although improvements have been made in the last years in the process of disease notification and data insertion in SINAN, there is still scarce training of professionals and little integration of epidemiological surveillance actions.

Brazil still lacks more reliable epidemiological data on occupational skin diseases and their implications in occupational health practice. Delay in the diagnosis of occupational skin diseases and the low number of notified cases to information systems have social and financial repercussions on professional and personal lives of workers.

To ensure good health for workers in developing countries, it is necessary to invest in occupational epidemiological studies in the area, so that new public policies can be developed based on the actual health situation. Occupational dermatology is fundamental for the development of public health policies.

This study aimed to analyze the panorama of work-related skin diseases in Brazil. The Brazilian notification system has been improving since 2007, progressively providing better data.

With regard to surveillance, follow-up, and treatment of ODs, specific training of health professionals can be a valuable action. Other studies are required to improve the accuracy of public health diagnosis in occupational dermatoses in Brazil. $\square$

\section{REFERENCES}

1. Duarte I, Rotter A, Lazzarini R. Frequency of occupational contact dermatitis in an ambulatory of dermatologic allergy. An Bras Dermatol. 2010;85:455-9.

2. Alchorne Ade 0, Alchorne MM, Silva MM. Occupational dermatosis. An Bras Dermatol. 2010;85:137-45

3. Cdc.gov [Internet]. Centers for Disease Control and Prevention. The National Institute for Occupational Safety and Health (NIOSH). Skin Exposures \& Effects. 2013. [cited 2017 Jun 18]. Available from: http://www.cdc.gov/niosh/topics/skin/

4. Beltrani VS. Occupational dermatoses. Curr Opin Allergy Clin Immunol. 2003:3:115-23.

5. Previdencia.gov.br [Internet]. Comunicação de Acidente de Trabalho - CAT [acesso 24 jun 2017]. Disponível em: http://www.previdencia.gov.br/servicosao-cidadao/todos-os-servicos/comunicacao-de-acidente-de-trabalho/

6. Saude.gov.br [Internet]. Sistema de Informação de Agravos de Notificação [acesso 16 Jun 2017]. Disponível em: http://portalsinan.saude.gov.br/drtdermatoses-ocupacionais

7. Gawkrodger DJ. Patch testing in occupational dermatology. Occup Environ Med 2001;58:823-8.

8. Livesley EJ, Rushton L, English JS, Williams HC. The prevalence of occupationa dermatitis in the UK printing industry. Occup Environ Med. 2002;59:487-92.

9. Chen $\mathrm{Y}$, Turner S, McNamee R, Ramsay CN, Agius RM.. The reported incidence of work-related ill-health in Scotland (2002-2003). Occup Med (Lond). 2005; $55: 252-61$

10. Bradshaw L, Harris-Roberts J, Bowen J, Rahman S, Fishwick D. Self-reported work-related symptoms in hairdressers. Occup Med (Lond). 2011;61:328-34.

11. Agner T. Noninvasive measuring methods for the investigation of irritant patch test

reactions. A study of patients with hand eczema, atopic dermatitis and controls. Acta Derm Venereol Suppl (Stockh). 1992;173:1-26.

12. Duarte I, Terumi Nakano J, Lazzarini R. Hand eczema: evaluation of 250 patients Am J Contact Dermat. 1998;9:216-23.

13. Shiao JS, Sheu HM, Chen CJ, Tsai PJ, Guo YL. Prevalence and risk factors of occupational hand dermatitis in electronics workers. Toxicol Ind Health. 2004;20:1-7.

14. Ulrich C, Salavastru C, Agner T, Bauer A, Brans R, Crepy MN, et al. The European Status Quo in legal recognition and patient-care services of occupational skin cancer. J Eur Acad Dermatol Venereol. 2016;30:46-51.

15. Diepgen TL. Occupational skin diseases. J Dtsch Dermatol Ges. 2012;10:297313.

16. Fartasch M, Diepgen TL, Schmitt J, Drexler H. The relationship between occupational sun exposure and non-melanoma skin cancer: clinical basics, epidemiology, occupational disease evaluation, and prevention. Dtsch Arztebl Int. 2012;109:715-20.

17. Carøe TK, Ebbehøj NE, Wulf HC, Agner T. Occupational skin cancer may be underreported. Dan Med J. 2013;60:A4624.

18. Li LF, Guo J, Wang J. Environmental contact factors in eczema and the results of patch testing Chinese patients with a modified European standard series of allergens. Contact Dermatitis. 2004:51:22-5.

19. White IR. ABC of work related disorders. Occupational dermatitis. BMJ 1996;313:487-9.

20. Cohen DE. Contact dermatitis: a quarter century perspective. J Am Acad Dermatol. 2004;51:S60-3.

How to cite this article: Lise MLZ, Feijó FR, Lise MLZ, Lise CRZ, Campos LCE. Occupational dermatoses reported in Brazil from 2007 to 2014. An Bras Dermatol. 2018;93(1):27-32. 